See Article page $\mathrm{XXX}$.

\section{Commentary: Sternal wound complications and internal mammary harvesting technique: An unresolved debate}

\author{
Sameer A. Hirji, MD, MPH, ${ }^{a}$ Hiba Ghandour, MD, ${ }^{b}$ \\ and George Tolis, Jr, MD
}

Sternal wound complications (SWCs) following coronary artery bypass grafting $(\mathrm{CABG})$ are a dreaded complication. Risk factors include diabetes, obesity, female sex, older age, preoperative hemodynamic instability, and renal failure requiring dialysis. ${ }^{1,2}$ Despite the known short-term implications of deep sternal wound infections (DSWI), ${ }^{3}$ the longterm impact is largely unknown and not well elucidated in the literature. For instance, in two 10-year follow-up studies of 36,078 and 3760 patients respectively, DSWI following CABG was significantly associated with long-term mortality. ${ }^{2,4}$ Conversely, in a propensity analysis of 7978 patients, DSWIs post-CABG were not significantly associated with worse long-term survival, ${ }^{5}$ leaving the cardiac surgical community at a crossroads in the context of single versus multiarterial revascularization.

We read with great interest the post hoc analysis of the randomized arterial revascularization trial by Gaudino and colleagues, ${ }^{6}$ which examined whether an association between SWCs and 10-year mortality following CABG exists. Patients were stratified according to presence or absence of postoperative SWCs. Of the 3102 patients included with a median follow-up time of 10 years, the incidence of SWC was $3.7 \%$ (115 patients), including $74 \%$ of patients with

\footnotetext{
From the ${ }^{\text {a Division }}$ of Thoracic and Cardiac Surgery, Department of Surgery, Brigham and Women's Hospital, Harvard Medical School, Boston, Mass; and ${ }^{\mathrm{b}}$ Department of Thoracic and Cardiovascular Surgery, Heart and Vascular Institute, Cleveland Clinic, Cleveland, Ohio

Disclosures: S.H. is a consultant for Encare EIAS system. All other authors reported no conflicts of interest.

The Journal policy requires editors and reviewers to disclose conflicts of interest and to decline handling or reviewing manuscripts for which they may have a conflict of interest. The editors and reviewers of this article have no conflicts of interest.

Drs Hirji and Ghandour contributed equally to this article.

Received for publication Nov 26, 2021; revisions received Nov 26, 2021; accepted for publication Nov 30, 2021

Address for reprints: George Tolis, Jr, MD, Division of Thoracic and Cardiac Surgery, Brigham and Women's Hospital, Harvard Medical School, 15 Francis St, Boston, MA 02115 (E-mail: gtolis@bwh.harvard.edu).

J Thorac Cardiovasc Surg 2021; $\mathbf{\square}: 1-2$

$0022-5223 / \$ 36.00$

Copyright (c) 2021 by The American Association for Thoracic Surgery

https://doi.org/10.1016/j.jtcvs.2021.11.070
}

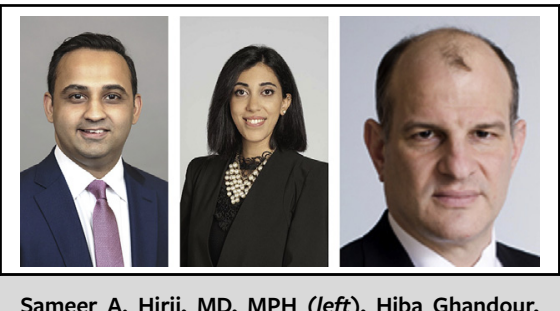

Sameer A. Hirji, MD, MPH (left), Hiba Ghandour, MD (middle), and George Tolis, Jr, MD (right)

\section{CENTRAL MESSAGE \\ While the occurrence of sternal wound complications has been shown to be associated with long-term mortality, further data from randomized trials are war- ranted to establish clinical equipoise.}

DSWI. The independent predictors of SWCs were the presence of diabetes, female sex, history of stroke, and history of bilateral internal thoracic artery (ITA) grafting. Interestingly, the use of skeletonization was not associated with the occurrence of SWC in the multivariable regression model. However, the occurrence of SWC was independently associated with long-term mortality.

The findings of this post-hoc analysis should be interpreted with caution, given the limitations inherent to its design: it can neither conform to the population nor the randomization model to reliably draw statistical inferences. Furthermore, data on harvesting technique were available in only approximately two-thirds of patients. Finally, additional confounders such as surgeon experience and the impact of patient crossover influence the interpretability of the study findings. However, this study provides some food for thought and adds to the growing discussion regarding the optimal ITA-harvesting technique (pedicled vs skeletonized) within the larger debate regarding single versus multiarterial grafting. The skeletonization approach has been shown to reduce the risk of sternal complications, especially in patients at risk of DSWI. ${ }^{7,8}$ One recent study using the Society of Thoracic Surgeons' Database further demonstrated comparable operative mortality between bilateral and single ITA but did show a 2 -fold risk of DSWI with bilateral ITA harvesting. To further complicate this debate, a recent post hoc analysis of the COMPASS (Cardiovascular Outcomes for People Using Anticoagulation Strategies) randomized clinical trial showed 
that the skeletonized technique was associated with a greater rate of graft occlusion and worse clinical outcomes than the pedicled technique. ${ }^{9}$ Considering all of this, the bottom line is that there is an urgent need for more randomized trials to assess the safety and patency of the skeletonized approach in the context of multiarterial total revascularization. Hopefully, the results of the ongoing ROMA (Randomized comparison of the Outcome of single vs Multiple Arterial grafts) trial will shed some light to this unresolved debate. ${ }^{10}$

\section{References}

1. Braxton JH, Marrin CA, McGrath PD, Ross CS, Morton JR, Norotsky M, et al. Mediastinitis and long-term survival after coronary artery bypass graft surgery. Ann Thorac Surg. 2000;70:2004-7.

2. Toumpoulis IK, Anagnostopoulos CE, Derose JJ Jr, Swistel DG. The impact of deep sternal wound infection on long-term survival after coronary artery bypass grafting. Chest. 2005;127:464-71.

3. Hirji S, Shah R, Shah S, Okoh A, Seese L, Yazdchi F, et al. Wound complications and 30-day readmissions after single and bilateral internal mammary grafting: analysis of the Nationwide Readmissions database. J Card Surg. 2021;36:74-81.
4. Braxton JH, Marrin CA, McGrath PD, Morton JR, Norotsky M, Charlesworth DC, et al. 10-year follow-up of patients with and without mediastinitis. Semin Thorac Cardiovasc Surg. 2004;16:70-6.

5. Cayci C, Russo M, Cheema FH, Martens T, Ozcan V, Argenziano M, et al. Risk analysis of deep sternal wound infections and their impact on long-term survival: a propensity analysis. Ann Plast Surg. 2008;61:294-301.

6. Gaudino M, Audisio K, Rahouma, et al. Association between sternal wound complications and 10-year mortality following coronary artery bypass grafting. $J$ Thorac Cardiovasc Surg. XXX, 2021 [Epub ahead of print].

7. Gaudino M, Bakaeen F, Benedetto U, Rahouma M, Di Franco A, Tam DY, et al. Use rate and outcome in bilateral internal thoracic artery grafting: insights from a systematic review and meta-analysis. J Am Heart Assoc. 2018; 7:e009361.

8. Deo SV, Shah IK, Dunlay SM, Erwin PJ, Locker C, Altarabsheh SE, et al. Bilateral internal thoracic artery harvest and deep sternal wound infection in diabetic patients. Ann Thorac Surg. 2013;95:862-9.

9. Lamy A, Browne A, Sheth T, Zheng Z, Dagenais F, Noiseux N, et al. Skeletonized vs pedicled internal mammary artery graft harvesting in coronary artery bypass surgery: a post hoc analysis from the COMPASS trial. JAMA Cardiol. 2021;6:1-8.

10. Gaudino M. Randomized comparison of the clinical outcome of single versus multiple arterial grafts: the ROMA Trial. ClinicalTrials.gov Identifier: NCT03217006. Accessed November 24, 2021. https://clinicaltrials.gov/ct2/ show/NCT03217006 